\title{
Combination Therapy with Ciprofloxacin plus Azlocillin against Pseudomonas aeruginosa: Effect of Simultaneous versus Staggered Administration in an In Vitro Model of Infection
}

\author{
Michael N. Dudley, Juerg Blaser, Deborah Gilbert, \\ Kenneth H. Mayer, and Stephen H. Zinner
}

Antiinfective Pharmacology Research Unit, University of Rhode Island College of Pharmacy and Roger Williams Medical Center; Division of Infectious Diseases, Brown University. Roger Williams, and Memorial Hospitals. Providence and Pawtucket, Rhode Island; Department fuer Innere Medizin. Universitaetsspital, Zurich, Switzerland

\begin{abstract}
The effect of dose scheduling on the pharmacodynamics of simulated human doses of ciprofloxacin (200 mg intravenously [iv] every $12 \mathrm{~h}$ ) and azlocillin $(4 \mathrm{~g}$ iv every $12 \mathrm{~h}$ ) alone or in combination against Pseudomonas aeruginosa was studied in a two-compartment in vitro kinetic model of infection. Studies with the two drugs in combination were compared using simultaneous or staggered (first doses of each drug were administered $6 \mathrm{~h}$ apart) dosing schedules. Bacterial regrowth and resistance were prevented by all combination dosing schedules; however, the simultaneous regimen consistently provided the greatest extent of killing for all strains, particularly in those initially resistant to ciprofloxacin. These enhanced effects of the combination were corroborated by an increase in the peak and duration of bactericidal activity in the analogous "serum" compartment of the model. These data show the potential usefulness of simultaneous dosing of an antipseudomonal $\beta$-lactam with ciprofloxacin against $P$. aeruginosa.
\end{abstract}

Several new fluoroquinolones have been developed that have enhanced activity against gram-negative aerobic bacteria. This enhanced in vitro activity has translated into clinical efficacy in the treatment of selected infections [1]. Ciprofloxacin is effective in the treatment of certain infections due to Pseudomonas aeruginosa [1, 2]; however, clinical failures and associated development of resistance during therapy have occurred $[3,4]$. These observations are consistent with in vitro studies that demonstrate selection of fluoroquinolone-resistant bacterial subpopulations during drug exposure $[5,6]$.

Antimicrobial combinations have been advanced as a means to prevent the selection of drug-resistant organisms during therapy for infection $[7,8]$. Additive and even synergistic activity between fluoroquinolones and $\beta$-lactam antibiotics have been detected using classical in vitro methods [911]. In view of these observations, the pharmacodynamics of ciprofloxacin and azlocillin alone or in combination were tested against four strains of $P$. aeruginosa with various degrees of susceptibility to each drug in an in vitro model of infection. In addition, the influence of the timing of dosing of each drug relative to another on bacterial killing was examined.

Received 26 November 1990; revised 13 May 1991.

Grant support: Miles Pharmaceuticals.

Reprints or correspondence: Dr. M. N. Dudley, Antiinfective Pharmacology Research Unit, University of Rhode Island College of Pharmacy \& Roger Williams Medical Center, 5th Floor, Nerth Campus, 825 Chalkstone Ave., Providence, RI 02908.

The Journal of Infectious Diseases 1991;164:499-506 (C) 1991 by The University of Chicago. All rights reserved. 0022-1899/91/6403-0009\$01.00

\section{Methods}

Bacteria. Four stable clinical isolates of $P$. aeruginosa were studied. Strains were selected on the basis of susceptibility to ciprofloxacin and azlocillin such that all possible combinations of susceptibility and resistance to one or both drugs would be tested (i.e., resistant to ciprofloxacin, azlocillin, neither, or both). Susceptibility testing was done using broth dilution in cation-supplemented Mueller-Hinton (MHB-S) broth with an inoculum of $\sim 10^{6} \mathrm{cfu} / \mathrm{ml}$ using standardized methods $[12,13]$. All strains were synergistically inhibited and killed by the drug combination according to checkerboard synergism testing; the fractional inhibitory (FIC) and fractional bactericidal concentration (FBC) indices, respectively, were $\leqslant 0.5$ for all strains (table 1).

In vitro model of infection and dosage regimens. The in vitro model of infection used was a two-compartment system using hollow fiber capillary units (Amicon, Danvers, MA) as previously described [14]. Briefly, each unit consists of a plastic tube through which a bundle of polysulfone fibers is passed. Growth medium containing drug is circulated through the lumen of the fibers from a reservoir; this loop is the analogous "serum" or central compartment. Medium is also added to the chamber exterior to the capillary fibers and inoculated with the organism to be studied. The hollow fibers retain particles that are $>10,000$ molecular weight; therefore, drug can diffuse to this analogous "tissue" or peripheral compartment. Paired pharmacokinetic (i.e., drug concentrations) and pharmacodynamic (i.e., bacterial colony-forming units [cfu]) observations are made periodically for these compartments. Drug concentrations are decayed from the central compartment at a rate adjusted for pharmacokinetic properties in humans by diluting the central reservoir with drugfree medium.

Serum drug concentrations for intravenous (iv) doses of ciprofloxacin (200 $\mathrm{mg}, 30-\mathrm{min}$ infusion) [15] and azlocillin $(4 \mathrm{~g}$, iv 
Table 1. Antibiotic susceptibility and maximum bactericidal titer of Pseudomonas aeruginosa strains measured in the central compartment of the in vitro model during the first $12 \mathrm{~h}$.

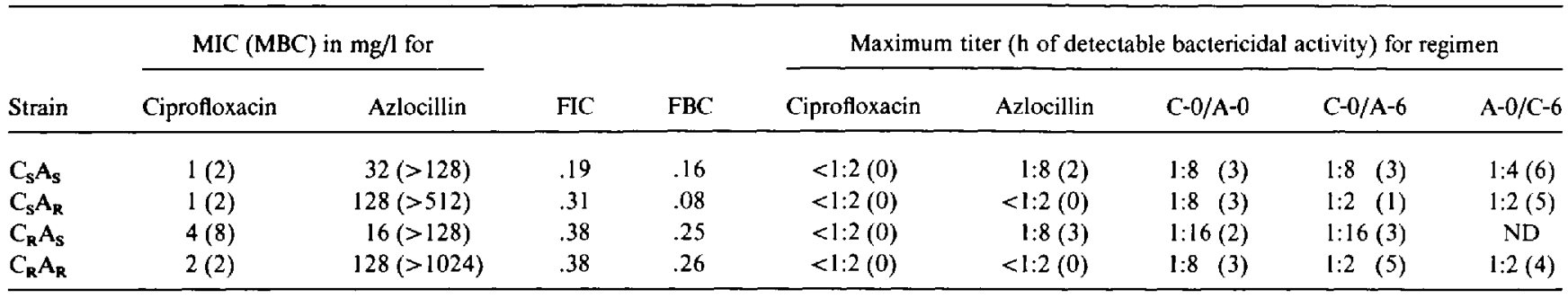

NOTE. FIC, fractional inhibitory concentration; FBC, fractional bactericidal concentration index; C-0/A-0, both drugs given simultaneously; C-0/A-6, ciprofloxacin (C) given at 0 and $12 \mathrm{~h}$, azlocillin (A) given at 6 and $18 \mathrm{~h} ; \mathrm{A}-0 / \mathrm{C}-6, \mathrm{~A}$ given at 0 and $12 \mathrm{~h}, \mathrm{C}$ given at 6 and $18 \mathrm{~h}$; S, susceptible; R, resistant; ND, not done.

bolus) [16] were simulated in the central compartment of the model and were tested alone or in combination. The dosing interval for each drug was $12 \mathrm{~h}$ when used alone or in combination.

Experiments were conducted with each drug alone and in combination. Three strategies for administering the drugs in combination were compared. Simultaneous administration of both drugs at 0 and $12 \mathrm{~h}(\mathrm{C}-0 / \mathrm{A}-0)$ or staggered administration was tested. For staggered regimens, ciprofloxacin was given at 0 and $12 \mathrm{~h}$ and azlocillin at 6 and $18 \mathrm{~h}(\mathrm{C}-0 / \mathrm{A}-6)$ or conversely with azlocillin given first (A-0/C-6).

The bacterial inoculum was prepared from previously frozen inocula by thawing, diluting with an equal part of fresh MHB-S, and incubating at $37^{\circ} \mathrm{C}$ for $1-2 \mathrm{~h}$ to bring organisms to the log-linear growth phase. A sample of this mixture was then introduced into the peripheral chambers of the model, which contained 7-10 ml of MHB-S. Organisms were allowed to grow in the chambers for $\sim 1$ h to reach a final target inoculum of $\sim 2 \times$ $10^{6} \mathrm{cfu} / \mathrm{ml}$.

Pharmacodynamic and pharmacokinetic measurements. Samples $(0.5 \mathrm{ml})$ were collected from the peripheral chambers at various times after drug administration to determine drug and bacterial concentrations. Bacterial counts $(\mathrm{cfu} / \mathrm{ml})$ were determined by serial 10 -fold dilution of sample in cold saline and inoculation (in triplicate) of $20 \mu$ l onto Mueller-Hinton agar (MHA). Small numbers of bacteria were counted by placing 100 $\mu \mathrm{l}$ of sample into $\sim 10 \mathrm{ml}$ of cold saline and filtering this mixture through a $0.45-\mu \mathrm{m}$ filter (Millipore, Bedford, MA). The filter was then placed aseptically on drug-free MHA, incubated, and the colonies counted. In selected experiments, samples collected at 0,12 , and $24 \mathrm{~h}$ were also processed on MHA containing 1-8 mg/l of ciprofloxacin or $64-512 \mathrm{mg} / \mathrm{l}$ of azlocillin, respectively, to detect drug-resistant bacterial subpopulations. The limit for detection was $10 \mathrm{cfu} / \mathrm{ml}$.

Samples in the peripheral and central compartments of the model were assayed for ciprofloxacin and azlocillin using an agar-well diffusion assay, Bacillus subtilis was used for measurement of azlocillin concentrations; assay validation studies showed no interference of this assay by up to $1.0 \mathrm{mg} / 1$ of ciprofloxacin. Klebsiella pneumoniae ATCC 13883 was used in assays for ciprofloxacin concentration; samples from combination experiments with azlocillin were diluted with $\beta$-lactamase (Difco, Detroit) to prevent interference by azlocillin.

Samples from the central compartment were also assayed for bactericidal activity against each organism. The microdilution technique using MHB-S as the diluent was used for these studies [17]. Bacterial inocula were prepared from frozen samples as described. Criteria for a bactericidal end point were those of Pearson et al. [18].

Statistics. Differences between regimens in the change in log cfu/ml were compared using Peritz' $F$ test [19]; two-tailed differences with a $P<.05$ (with adjustment for multiple comparisons) were considered statistically significant.

\section{Results}

\section{Pharmacokinetics}

Figures $I$ and 2 depict ciprofloxacin and azlocillin concentrations in the central and peripheral chambers of the model. Mean peak ciprofloxacin concentrations in the central and peripheral chambers after the first dose were 1.1 and 0.72 $\mathrm{mg} / \mathrm{l}$, respectively. The concentrations in the central compartment declined exponentially, with a 4-h half-life. Mean peak azlocillin concentrations in the peripheral chambers occurred at $\sim 2 \mathrm{~h}$ and averaged $102 \mathrm{mg} / \mathrm{l}$. The half-life for elimination of azlocillin from the central compartment was $1.2 \mathrm{~h}$. As shown in figure 2 , the $\mathrm{C}-0 / \mathrm{A}-0$ regimen resulted in exposure of bacteria to high concentrations of both drugs simultaneously followed by periods of low levels, whereas staggered administration resulted in more sustained exposure of bacteria to either drug.

\section{Pharmacodynamics}

The effects of single-drug and all combination treatments on each strain are shown in figure 3. All organisms grew well in the model during control experiments (no drug exposure).

Single-agent therapy. Rapid bacterial killing by ciprofloxacin alone was observed in three of four strains; on average, a 2-3 $\log$ reduction in cfu/ml occurred within $6 \mathrm{~h}$. In contrast, no bacterial killing was observed with the strain most resistant to ciprofloxacin $\left(C_{R} A_{S}\right)$. After 4-6 h, bacterial regrowth was observed with the other three strains; the second dose of ciprofloxacin (at $12 \mathrm{~h}$ ) had no effect on bacterial regrowth. Analysis of bacteria growing on MHA containing ciprofloxa- 
Figure 1. Concentrations of ciprofloxacin (A) and azlocillin (B) in the central and peripheral chambers of the model for all experiments. Each point depicts mean of 2-15 samples; bars indicate $1 \mathrm{SD}$.
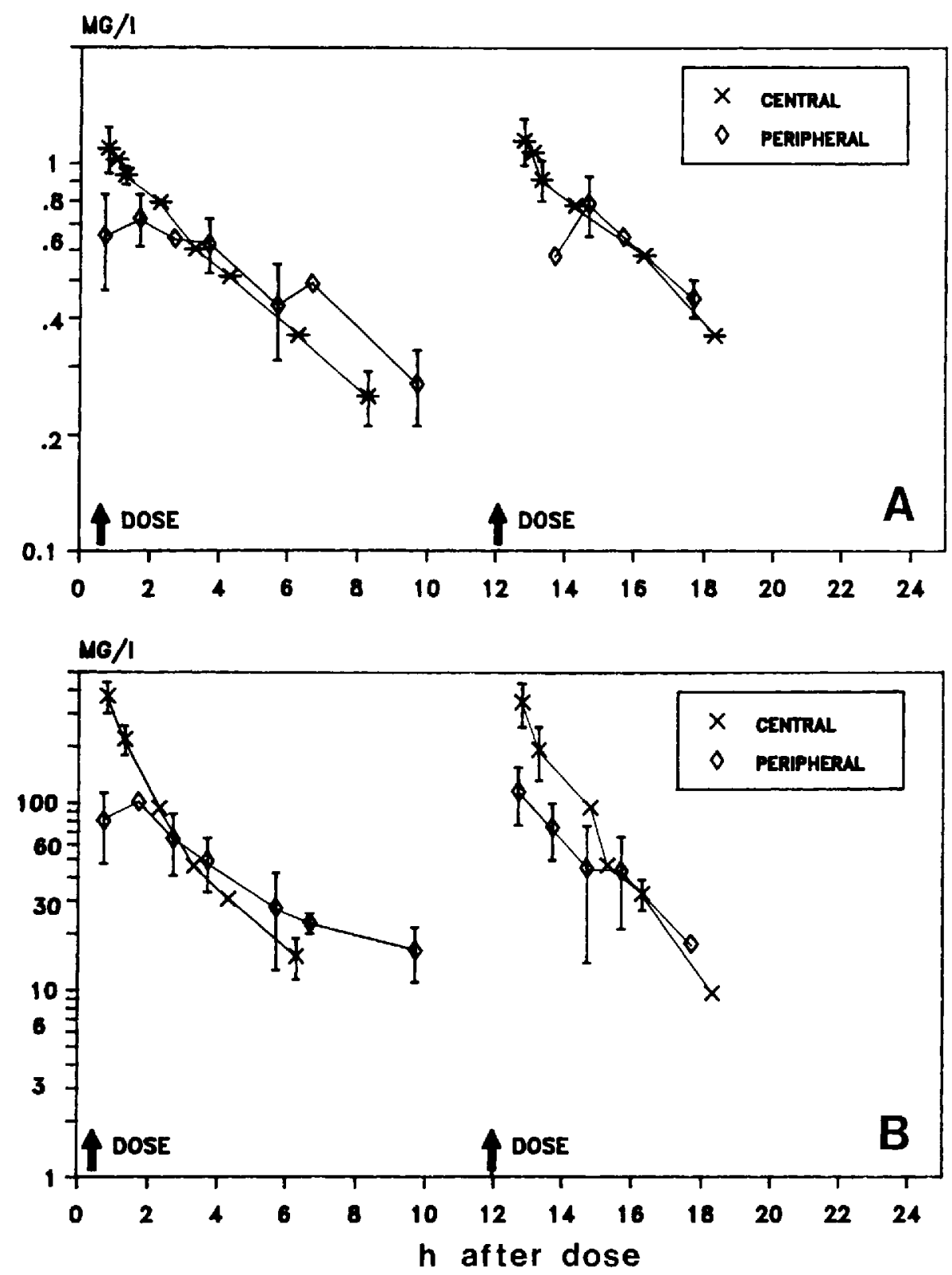

cin showed subpopulations resistant to peak or higher ciprofloxacin concentrations by 12 and $24 \mathrm{~h}$ (figure 4 ).

In contrast to ciprofloxacin, azlocillin alone produced a $2-3 \log$ reduction in $\mathrm{cfu} / \mathrm{ml}$ in all strains by $6 \mathrm{~h}$ (figure 3 ). This period was followed by relative bacteriostasis in strains initially susceptible (by MIC) to azlocillin. Bacterial strains initially resistant to azlocillin (MIC $>64 \mathrm{mg} / \mathrm{l}$ ) had regrowth patterns similar to that observed for ciprofloxacin; significant growth $\left(>10^{3} \mathrm{cfu} / \mathrm{ml}\right)$ was observed on MHA containing 64$256 \mathrm{mg} / \mathrm{l}$ of azlocillin at $12 \mathrm{~h}$, with $5-30 \times 10^{3} \mathrm{cfu} / \mathrm{ml}$ resistant to $512 \mathrm{mg} / \mathrm{l}$ by $24 \mathrm{~h}$.

Combination therapy. The selection of ciprofloxacin- or azlocillin-resistant bacteria was prevented by the combination of drugs. Only the staggered regimen of ciprofloxacin followed by azlocillin (C-0/A-6) failed to kill the strain most resistant to ciprofloxacin $\left(C_{R} A_{S}\right.$, figure 3$)$. For the strains doubly susceptible or resistant to study drugs, simultaneous administration resulted in enhanced bacterial killing by $6 \mathrm{~h}$ over that observed with the staggered- or single-drug regimens $(P<.05)$. For the remaining two strains, the reduction in cfu/milliliter by $6 \mathrm{~h}$ tended to reflect the activity of the more active (based on MIC breakpoints) drug; thus, either simultaneous or staggered dosing (with the more active drug given first) produced results at $6 \mathrm{~h}$, similar to that of the active drug alone.

Analysis of bacterial killing by $12 \mathrm{~h}$ with the simultaneous and staggered regimens allows for comparison of the cumulative effects of the first doses of each drug. Simultaneous dosing of ciprofloxacin plus azlocillin was superior to all singledrug regimens $(P<.05)$ except for azlocillin alone against 


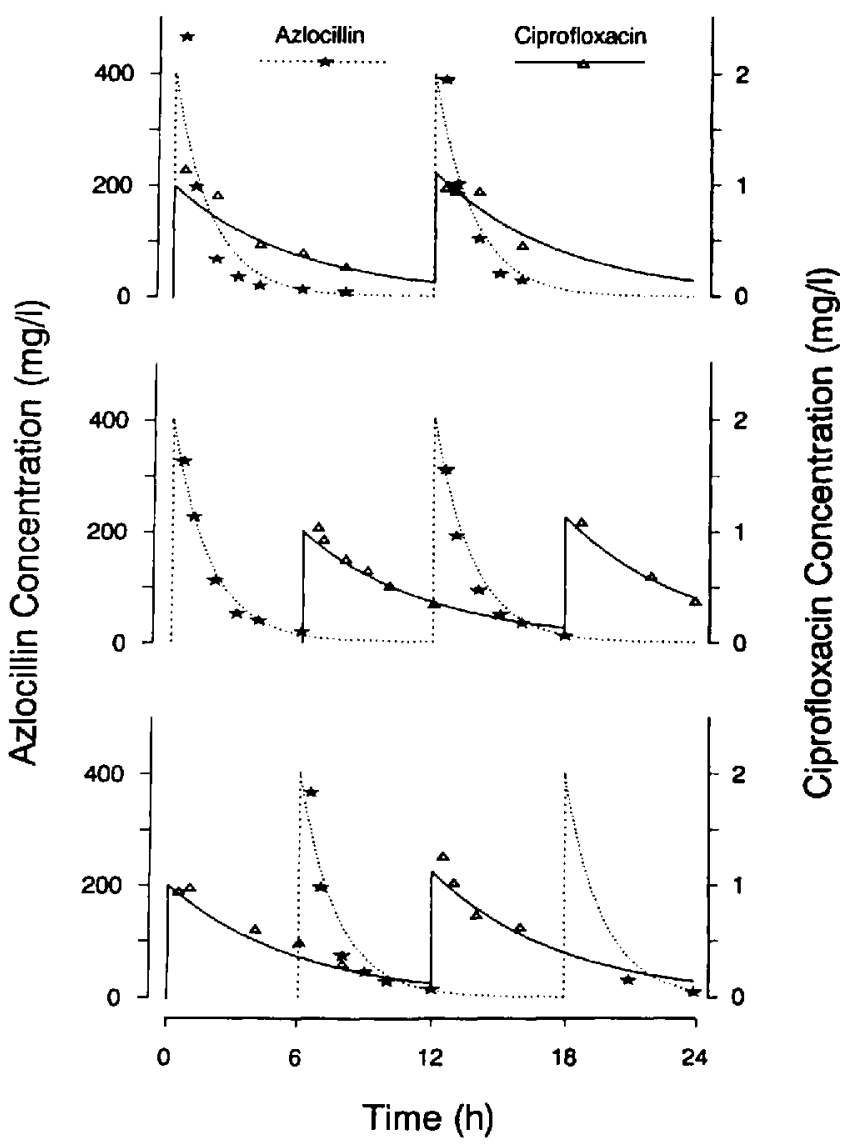

Figure 2. Simulated and measured concentrations of ciprofloxacin $(C)$ and azlocillin $(A)$ in the central compartment of the in vitro model for simultaneous (C-0/A-0, top) and staggered with azlocillin $(A-0 / C-6$, middle) or ciprofloxacin $(C-0 / A-6$, bottom) regimens of the combination.

$C_{s} A_{s}$. For strains initially resistant to ciprofloxacin, simultaneous administration was superior to all other regimens $(P<$ $.05)$.

In contrast to the first doses of each drug, the second 12-h dosing cycle of all combination regimens was bacteriostatic; the change in cfu/milliliter between 12 and $24 \mathrm{~h}$ ranged from a reduction of 1.2 to an increase of $0.2 \mathrm{log} \mathrm{cfu} / \mathrm{ml}$ in all strains and combination regimens. Thus, the differences in regimens were based on the extent of initial bacterial killing, which was greatest when the combination was administered simultaneously (i.e., C-0/A-0) for all strains. Reduction in cfu/milliliter over $24 \mathrm{~h}$ was significantly greater for combination therapy using any dosing schedule against the two azlocillin-susceptible and the doubly resistant strains than that observed for single-drug therapies $(P<.05)$; there were no differences between simultaneous and staggered regimens against the three strains $(P>.05)$. For the strain with the highest MIC to ciprofloxacin (i.e., $C_{R} A_{S}$ ), simultaneous and staggered administration with azlocillin given first (i.e., C-0/ $\mathrm{A}-0$ and $\mathrm{A}-0 / \mathrm{C}-6)$ produced similar reductions in cfu/milli- liter but were superior $(P<.05)$ to single drugs and the other staggered (i.e., $\mathrm{C}-0 / \mathrm{A}-6$ ) regimens.

Bactericidal activity. For the single-drug regimens, bactericidal activity in the central compartment was detected only with azlocillin against strains susceptible to this drug (table 1). In contrast, all combination-drug regimens resulted in detectable bactericidal activity. On average, the highest activity was observed when the combination was administered simultaneously; however, staggered dosing provided more prolonged periods of detectable bactericidal activity.

\section{Discussion}

The design of the in vitro model allowed the use of several methods to evaluate the relation between the pharmacokinetic and pharmacodynamic properties of each drug alone or in combination. The first dose of ciprofloxacin alone produced initial killing in three of four strains; the strain most resistant to ciprofloxacin $\left(C_{R} A_{S}, M I C=4 \mathrm{mg} / \mathrm{l}\right)$ was not killed by this drug. For the three other strains, a significant (>3log) reduction in cfu/milliliter was achieved during the first $6 \mathrm{~h}$ of drug exposure; this occurred even though drug concentrations in the peripheral compartment remained below the MIC throughout the experiment. Similar to previous reports [20], bacteria resistant to ciprofloxacin concentrations achieved in the central and peripheral chambers were clearly present in inocula recovered at $12 \mathrm{~h}$, even for the two strains initially susceptible to ciprofloxacin. Substantial initial bacterial killing with azlocillin was also observed in all strains, even though concentrations in peripheral chambers never exceeded the MIC for strains resistant to azlocillin based on MIC criteria (i.e., $C_{S} A_{R}$ and $C_{R} A_{R}$ ); however, regrowth patterns similar to that observed with ciprofloxacin alone occurred and persisted through subsequent doses of azlocillin. In contrast, regrowth did not occur after the first dose of azlocillin with the strains initially susceptible to azlocillin, even though concentrations were below the MIC by as early as $6 \mathrm{~h}$. These persistent inhibitory effects are consistent with previous in vitro observations of bacterial growth suppressed with subinhibitory drug concentrations after exposure to high, suprainhibitory drug concentrations [21].

The advantage of combination therapy with these drugs in our model was apparent by the lack of selection of ciprofloxacin-resistant bacterial subpopulations. All combination regimens resulted in a statistically significant greater reduction in bacterial counts ( $>2 \log \mathrm{cfu} / \mathrm{ml}$ ) by $24 \mathrm{~h}$ than that seen with single-drug regimens; these observations are compatible with previous studies on synergistic drug interactions in this model [22]. Notably, this enhanced effect was present in all strains, including those resistant to one or both drugs, indicating the potential clinical usefulness of this combination.

Previous studies of experimentally induced infections due to $P$. aeruginosa in several animal models of infection have variably demonstrated an advantage for combination ther- 

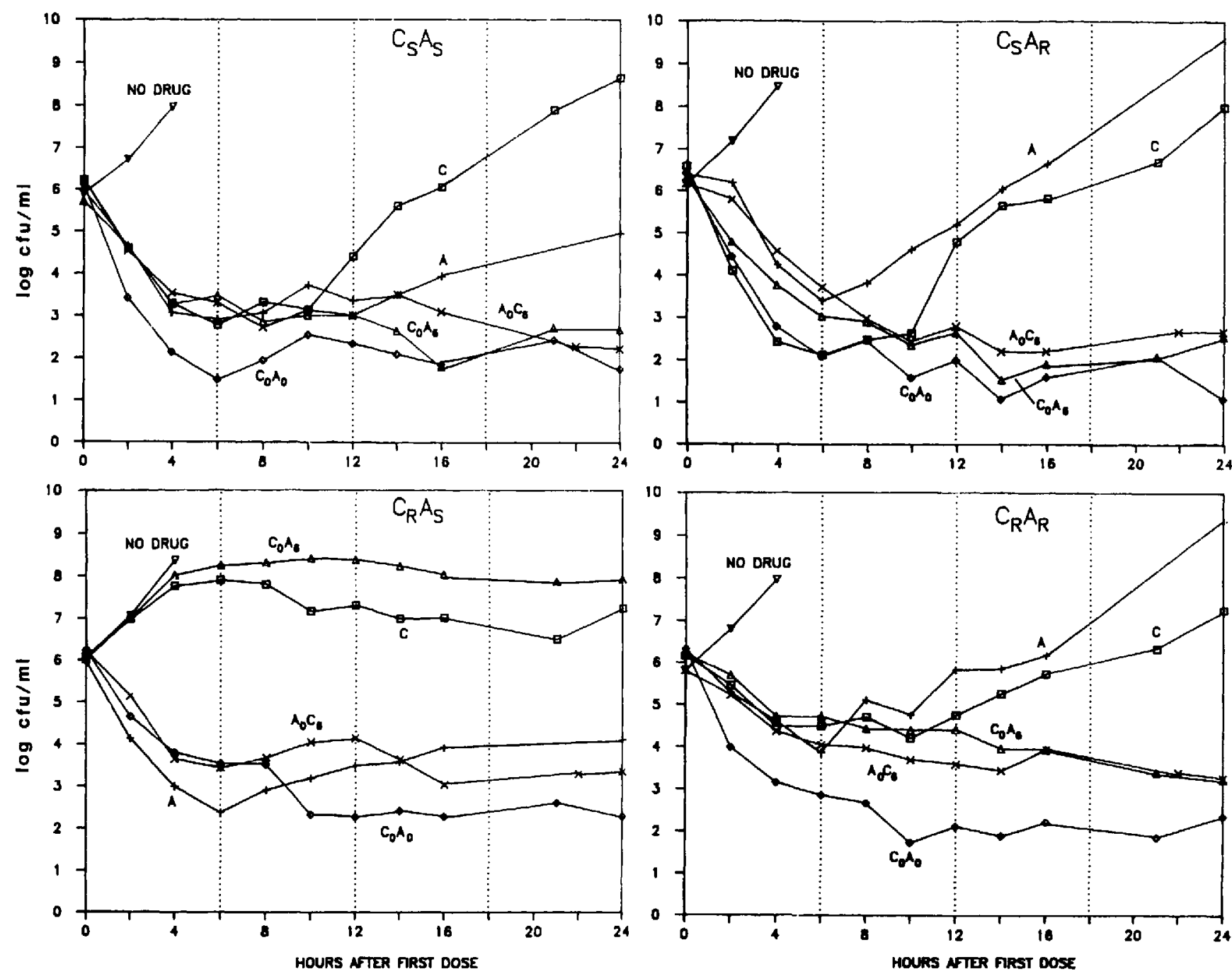

Figure 3. Pharmacodynamics of five regimens of ciprofloxacin (C) and azlocillin (A) alone or in combination against four strains of Psetudomonas aeruginosa. $\square$, ciprofloxacin alone; + , azlocillin alone; $\nabla$, simultaneous ciprofloxacin plus azlocillin (C-0/A-0); $\Delta, X$, staggered ciprofloxacin plus azlocillin, with either ciprofloxacin $(\triangle, C-0 / A-6)$ or azlocillin $(X, A-0 / C-6)$ given first. Each point depicts the mean of $2-4$ within or between day replications. Vertical lines at 6,12 , and $18 \mathrm{~h}$ identify dose events.

apy with a fluoroquinolone plus a $\beta$-lactam [23-29]. The benefit of adding azlocillin to ciprofloxacin therapy was particularly evident in studies using doses of ciprofloxacin that resulted in low ratios of the peak drug concentration to the MIC [23-26]; addition of azlocillin was associated with improved bacterial killing $[23,24]$ or survival $[25,26]$ or suppression of bacterial resistance to ciprofloxacin [23]. In contrast, other investigators concluded that adding an antipseudomonal penicillin to ciprofloxacin was not advantageous [27-29]. The discrepancies in outcome between different studies as well as those obtained in our model may stem from differences in initial bacterial inoculums used (critical to include drug-resistant subpopulations) [6, 27], assessment only of early bactericidal effects [29], or dosage regimens that produced higher ciprofloxacin [28] or lower $\beta$-lactam concentrations [27] in animals than those obtained in humans with usual doses. However, several examples of clinical failure and the development of fluoroquinolone resistance during combination therapy with a $\beta$-lactam have been reported $[30,31]$.

In view of differences in pharmacokinetic and pharmacodynamic properties between fluoroquinolones (longer elimination half-life, concentration-dependent killing, and postantibiotic effects) and ureidopenicillins (shorter elimination half-life, lack of significant postantibiotic effect, or relation between drug concentration and bacterial killing) [32], we examined the effect of the timing of doses of each drug relative to another to analyze the effect of various drug concentrations (and ratios to each other) on bacterial killing and regrowth. Simultaneous administration of both drugs was associated either with greater initial killing of bacteria over the first $6 \mathrm{~h}$ or was similar to that observed for the more active 

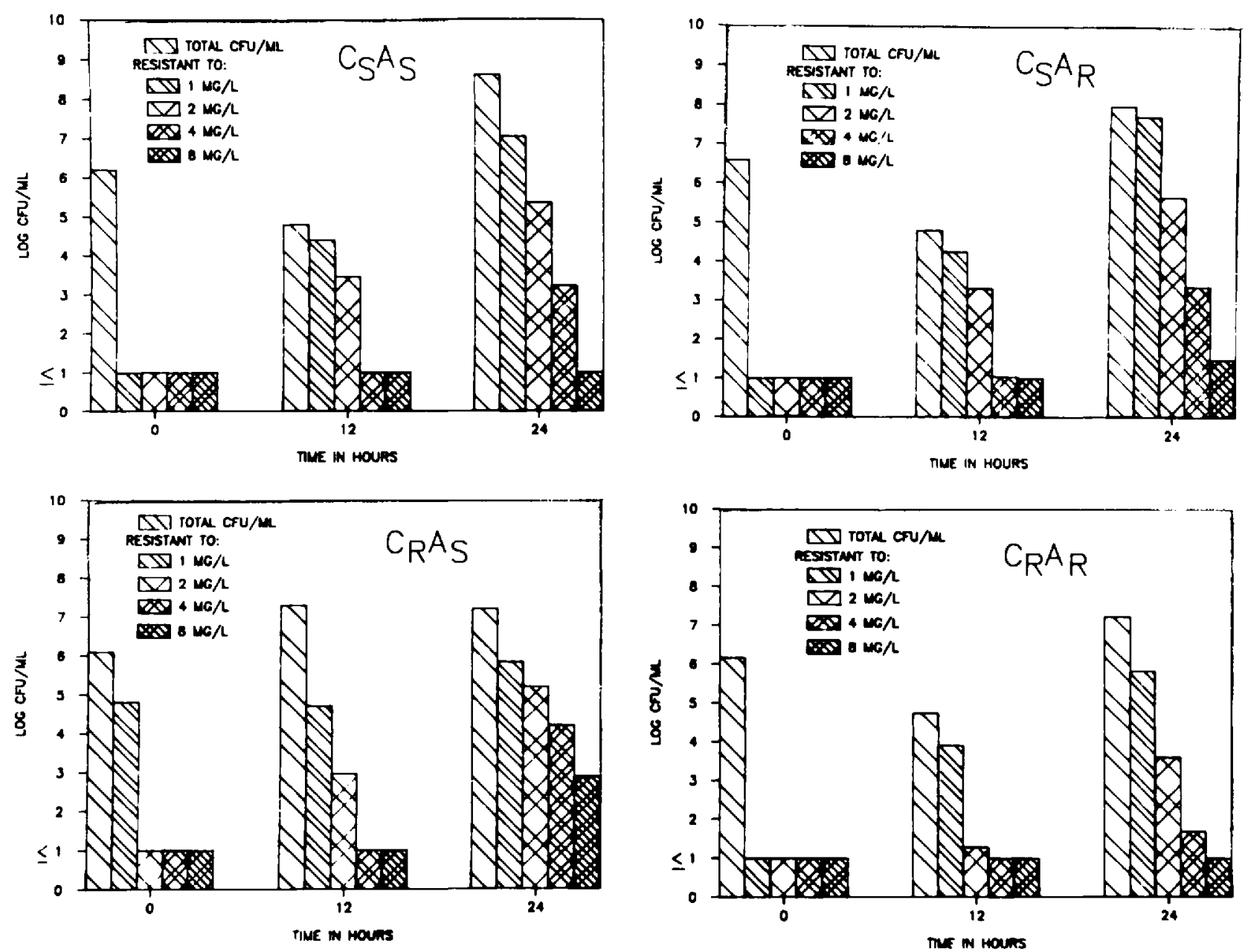

Figure 4. Total bacterial counts and subpopulations resistant (R) to $1-8 \mathrm{mg} / \mathrm{l}$ of ciprofloxacin (C) in samples collected from peripheral chamber of in vitro model at 0,12 , and $24 \mathrm{~h}$ after exposure to simulated doses of ciprofloxacin (200 mg iv) alone. A, azlocillin; $\mathrm{S}$, susceptible.

(based on MIC susceptibility criteria) drug alone. For the strain most resistant to ciprofloxacin, simultaneous dosing of the combination was critical because bacterial killing could not be initiated with ciprofloxacin alone. Overall, simultaneous administration provided the most consistent bactericidal effects and did not vary according to the in vitro susceptibility of each strain. Despite a significant reduction in cfu/milliliter during the first dosing cycle for the simultaneous regimen, subsequent doses at or after $12 \mathrm{~h}$ for all staggered regimens resulted only in bacteriostasis.

The importance of timing of doses in use of antibiotic combinations in the treatment of gram-negative bacillary infections has received little study. Bacterial killing with gentamicin and piperacillin in in vitro timed-kill curve experiments was greatest when concentrations of each drug tested corresponded to those after simultaneous administration of both drugs [33]. In contrast, studies using in vitro kinetic models of infection demonstrated greater killing of drug-susceptible $P$. aeruginosa when the first dose of an aminoglycoside was followed 2-4 $\mathrm{h}$ later by the first dose of an antipseudomonal penicillin $[34,35]$; however, when azlocillin preceded the first dose of sisomicin by $2 \mathrm{~h}$, less killing was observed [34]. Recent studies using a model similar to that in the present study with amikacin and ceftriaxone against ceftriaxonesusceptible or -resistant strains of $P$. aeruginosa demonstrated no significant differences in bacterial killing when single daily doses were given alone or were staggered by $6 \mathrm{~h}$ [36]. In contrast, simultaneous administration of ticarcillin and gentamicin by continuous infusion compared with bolus administration of one or both drugs resulted in more bacterial killing and less mortality in rats infected with a strain of $P$. aeruginosa resistant to both drugs but synergistically inhibited [37]. These data and those from the current study suggest the need for adequate contact time between drugs in vivo for synergistic killing of drug-resistant bacteria.

Analysis of serum bactericidal titers on samples from the central compartment confirmed previous in vivo observations on the poor serum bactericidal activity of iv doses of 
ciprofloxacin $(200 \mathrm{mg}$ ) alone against $P$. aeruginosa [17] and the additive or synergistic activity with azlocillin at clinically relevant concentrations [38]. These measurements of the central compartment of the model also provided some insight into pharmacokinetic measurements linked to the kinetics of bacterial killing and the selection of bacterial resistance. Simultaneous dosing of both drugs increased the maximum bactericidal titer and the duration of detectable bactericidal activity; increasing both the peak and duration of effective drug concentrations would be expected to enhance the pharmacodynamic properties associated with either drug alone. In contrast, staggered dosing of the two drugs generally increased the duration, but not the intensity, of activity. In view of the results from the peripheral chambers of the model, these data confirm the concept that high peak bactericidal activity early in the course of therapy is important in the treatment of infections due to $P$. aeruginosa with fluoroquinolones $[25,39,40]$. These data support further clinical evaluation of these or higher doses of ciprofloxacin combined with an antipseudomonal $\beta$-lactam in the treatment of serious infections due to $P$. aeruginosa.

\section{Acknowledgment}

We thank Martin Kuepker for technical assistance.

\section{References}

1. Sanders WE, Sanders CC. eds. Fluoroquinolones in the treatment of infectious diseases. Glenview, IL: Physicians and Scientists Publishing, 1990.

2. Eron LJ, Harvey L, Hixon DL, Poretz DM. Ciprofloxacin therapy of infection caused by $P$. aeruginosa and other resistant bacteria. Antimicrob Agents Chemother 1985;27:308-10.

3. Salh B. Webb AK. Ciprofloxacin resistance. Lancet 1987;1:749-50.

4. Roberts CM. Batten J, Hodson ME. Ciprofloxacin-resistant Pseudomonas. Lancet 1985; 1:1442.

5. Daikos GL. Lolans VT. Jackson GG. Alterations in outer membrane proteins of $P$. aeruginosa associated with selective resistance to quinolones. Antimicrob Agents Chemother 1988:32:785-7.

6. Wolfson JS, Hooper DC. Bacterial resistance to quinolones: mechanisms and clinical importance. Rev Infect Dis 1989; 1 1:S960-8.

7. Michea-Hamzehpour M, Pechere JC, Marchou B, Auckenthaler R. Combination therapy: a way to limit emergence of resistance? Am $J$ Med 1986;80(suppl 6B): 138-42.

8. Pechere JC, Marchou B, Michea-Hamzehpour M, Auckenthaler R. Emergence of resistance after therapy with antibiotics used alone or combined in a murine model. J Antimicrob Chemother 1986; 17(suppl A): 11-8.

9. Neu HC. Synergy of fluoroquinolones with other antimicrobial agents. Rev Infect Dis 1989;1 1(suppl 5):1025-35.

10. Eliopoulos GM. Eliopoulos CT. Ciprofloxacin in combination with other antimicrobials. Am J Med 1989;87(suppl 5A): 17S-22.

11. Lewin CS, Smith JT. Interactions of the 4-quinolones with other antibacterials. J Med Microbiol 1989;29:221-7.

12. Blaser J. Dudley MN, Gilbert D, Zinner SH. Influence of medium and method on the in vitro susceptibility of Pseudomonas aeruginosa and other bacteria to ciprofloxacin and enoxacin. Antimicrob Agents Chemother 1986;29:927-9.
13. National Committee for Clinical Laboratory Standards. Standard methods for dilution antimicrobial susceptibility tests for bacteria which grow aerobically: tentative standards. Villanova, PA: National Committee for Laboratory Standards. 1983; NCCLS document M7-T.

14. Blaser J, Stone BB, Zinner SH. Two compartment kinetic model with multiple artificial capillary units. J Antimicrob Chemother 1985; 15(suppl A): 131-7.

15. Dudley MN, Ericson J, Zinner SH. Effect of dose on serum pharmacokinetics of intravenous ciprofloxacin with identification and characterization of extravascular compartments using noncompartmental and compartmental pharmacokinetic models. Antimicrob Agents Chemother 1987;31:1782-6.

16. Bergan T. Review of the pharmacokinetics and dose dependency of azlocillin in normal subjects and patients with renal insufficiency. $J$ Antimicrob Chemother 1983;1 1(suppl B): 101-14.

17. Dudley MN, Mandler HD, Mayer KH, Zinner SH. Serum inhibitory and bactericidal activity of ciprofloxacin following intravenous administration. DICP 1989;23:456-9.

18. Pearson RD, Steigbigel RT, Davis HT, Chapman SW. Method for reliable determination of minimum lethal antibiotic combinations. Antimicrob Agents Chemother 1980; 18:699-708.

19. Harper JF. Peritz' $F$ test: basic program of a robust multiple comparison test for statistical analysis of all differences among group means. Comput Biol Med 1984; 14:437-45.

20. Dudley MN, Mandler H, Gilbert D, Ericson J, Mayer KH, Zinner SH. Pharmacokinetics and pharmacodynamics of intravenous ciprofloxacin. Am J Med 1987;82(suppl 4A):363-8.

21. Odenholt I, Holm SE, Cars O. Pharmacodynamic effects of subinhibitory antibiotic concentrations. Scand J Infect Dis 1991;74(suppl):94-101.

22. Blaser J. Interaction of antimicrobial combinations in vitro: the relativity of synergism. Scand J Infect Dis 1991;74(suppl):71-9.

23. Bamberger DM, Peterson LR, Gerding DN, Moody JA, Fasching CE. Ciprofloxacin, azlocillin, ceftizoxime and amikacin alone and in combination against gram-negative bacilli in an infected chamber model. J Antimicrob Chemother 1986;18:51-63.

24. Haller I. Evaluation of ciprofloxacin alone and in combination with other antibiotics in a murine model of thigh muscle infection. Am $\mathbf{J}$ Med 1987;82(suppl 4A):76-9.

25. Johnson M, Miniter P, Andriole VT. Comparative efficacy of ciprofloxacin, azlocillin, and tobramycin alone and in combination in experimental Pseudomonas sepsis. J Infect Dis 1987:155:783-8.

26. Chin NX, Jules K, Neu HC. Synergy with ciprofloxacin and azlocillin in vitro and in a neutropenic mouse model of infection. Eur $\mathbf{J}$ Clin Microbiol 1986;5:23-8.

27. Michea-Hamzehpour M, Auckenthaler R, Regamey P, Pechere JC. Resistance occurring after fluoroquinolone therapy of experimental $P$. aeruginosa peritonitis. Antimicrob Agents Chemother 1987; 31:1803-8

28. Thauvin C, Lecomte F, Le Boete I, Grise G, Lemeland JF. Efficacy of ciprofloxacin alone and in combination with azlocillin in experimental endocarditis due to Pseudomonas aeruginosa. Infection $1989 ; 17: 31-4$.

29. Kemmerich B, Small GJ, Pennington JE. Comparative evaluation of ciprofloxacin, enoxacin, and ofloxacin in experimental Pseudomonas aeruginosa pneumonia. Antimicrob Agents Chemother 1986; 29:395-9.

30. Scully BE, Nakatomi M, Ores C. Davidson S, Neu HC. Ciprofloxacin therapy in cystic fibrosis. Am J Med 1987;82(suppl 4A):196-201.

31. Desplaces N, Guttman L. Carlet J, Guibert J, Acar JF. The new quinolones and their combinations with other agents for therapy of severe infections. J Antimicrob Chemother 1986;17(suppl 2A):25-39.

32. Ebert SC, Craig WA. Pharmacodynamic properties of antibiotics: application to drug monitoring and dosage regimen design. Infect Control Hosp Epidemiol 1990;11:319-26. 
33. Tisdale JE, Pasko MT. Mylotte JM. Antipseudomonal activity of simulated infusions of gentamicin alone or with piperacillin assessed by serum bactericidal rate and area under the killing curve. Antimicrob Agents Chemother 1989;33:1500-5.

34. Guggenbichler JP, Allerberger F, Dietrich MP, Schmitzberger R, Semenitz E. Spaced administration of antibiotic combinations to eliminate Pseudomonas from sputum in cystic fibrosis. Lancet 1988;2:749-50

35. Haller I. Combined action of decreasing concentrations of azlocillin and sisomicin on Pseudomonas aeruginosa as assessed in a dynamic in vitro model. Infection 1982;10(suppl 3):229-33.

36. Dudley MN, Marchbanks CR, Gilbert D, Zinner SH. Pharmacodynamics and subpopulation analysis of single and combination therapy of

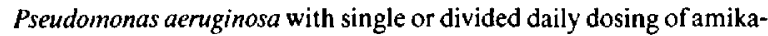
cin with simultaneous or staggered ceftriaxone [abstract]. Pharmacotherapy $1990 ; 10: 234$.
37. Mordenti JJ, Quintillani R, Nightingale CH. Combination antibiotic therapy: comparison of constant infusion and intermittent bolus dosing in an experimental animal model. J Antimicrob Chemother 1985; 15(suppl A):313-21.

38. Orlando PL, Barriere SL, Hindler JA, Frost RW. Serum bactericidal activity from intravenous ciprofloxacin and azlocillin given alone and in combination to healthy subjects. Diagn Microbiol Infect Dis 1990;13:93-7.

39. Blaser J, Stone BB, Groner MC. Zinner SH. Comparative study with enoxacin and netilmicin in a pharmacodynamic model to determine importance of the ratio of antibiotic peak concentration to MIC for bactericidal activity and the emergence of resistance. Antimicrob Agents Chemother 1987;31:1054-69.

40. Peloquin CA, Cumbo TJ, Nix DE, Sands MF, Schentag JJ. Evaluation of intravenous ciprofloxacin in patients with nosocomial lower respiratory tract infections. Arch Intern Med 1989;149:2269-73. 